\title{
Theory of SMEs financial risk prevention and control
}

\author{
Zhao Shuying \\ The College Of Business Administration \\ The International Office Of USTL \\ An Shan, China \\ e-mail: 1902764944@qq.com
}

\author{
Zeng Mei \\ The College Of Business Administration \\ The International Office Of USTL \\ An Shan, China \\ e-mail:zengmei1994@163.com
}

\begin{abstract}
With the rapid development of market-oriented economy, the SMEs face more and more fierce market competition. Financial risk exists everywhere which can't be avoid and has a certain influence on their production and management. The SMEs need to make a full understanding of the characteristics, the present situation and the causes of financial risk in order to survive in the market competition and put forward effective prevention and control measures, and thus lower the possibility of occurrence of risks to ensure their development. This article analyzes the importance and characteristics of enterprises at first, and then studies the present finance of our county enterprises and the causes of these risks, and finally discusses the prevention and control measures of enterprises financial risk.
\end{abstract}

Keywords-SMEs; financial risk; prevention; control

\section{INTRODUCTION}

In today's fierce competition in the market economic activities, the SMEs gradually developed into a major force for national economic and social development. Financial risk is one of the risks any enterprise can't avoid, therefore, the company managers can easily make financial decisions under the risky and uncertain situation. In the process of development, with various uncertain factors such as natural environment and social economic environment, the risks SMEs faced also gradually increase. In this case, we must take timely measures to ensure that SMEs in an invincible position in the market competition. Therefore, correct understanding of financial risk and presentation operable warning method of financial risk is of great significance.

\section{THE SUMMARY OF FINANCIAL RISK}

\section{A. The concept of financial risk}

Financial risk refers to that in the process of daily affairs, because of the interference of some external and internal factors, things don't develop with the expected phase deviation, therefore, this circumstance raises the risk that enterprises finance isn't normal as planned.

\section{B. The characteristics of financial risk}

\section{1) Objectivity}

Financial risk always exists and exists everywhere. It can't be transferred by man's will. Human are unable to avoid and eliminate it. But they can reduce loss and cope with the risk through various technical means and developing preventive measures . [1]

2) Uncertainty
Financial risk occurs only at a certain period or stage and men are unable to determine the period and stage. Thus illustrates the financial risk is uncertain also, which requires the enterprise managers must constantly strengthen the consciousness of risk, improve financial management so that they can reduce the possibility of the occurrence of the risk.

3) Comprehensive

Financial risk exists in all aspects of the enterprise financial management work including the raise, use and distribution of capital. This requires managers to fully focus on all aspects of the change, find risk timely, and take effective measures to control the spread of the risk.

\section{4) Duality}

Namely, the co-existence of loss and benefits. Corporate earnings and risk is equivalent, if enterprises want to have good profits, they will undertake a certain amount of risk. In a way, the returns and risk tend to be positively related. The greater the income they have, the greater the risk faced by them. On the contrary, the smaller the earnings the make, the greater the risk they face. [2]. Profits tend to be influenced by its operating condition, financial strategy and technology innovation and a series of factors, at the same time, it will be affected by its impact on the financial risk prevention strategy. Therefore, the more comprehensive strength they have, the more earnings they make. Therefore, enterprises should correctly handle the relationship between income and risk, using the financial risk to bring more benefit for the enterprise.

\section{THE PRESENT SITUATION OF OUR COUNTRY SMES FINANCE}

The financial risk of the SMEs in our country can be summarized as follows:

A. The financing difficulties and lack of working fund are the most common manifestation of SMEs financial risk.

Nowadays, many market unstable factors makes the SMEs production cost increase and the profits reduce. In the process of financing, SMEs need to consider the scale of financing, if their financing scale is too large, it will cause the waste of funds and increase the cost. And it may cause enterprises to debt more but have difficulty to repay which brings financial risk to the enterprises. In addition, the scale and the amount of capital of SMEs is small and they face a severe lack of working fund. 


\section{B. Nonstandard control inside the enterprise, lack of financial risk management institution.}

SMEs has so weak consciousness of the financial risk management that they cannot work out a set of strict and feasible financial management system. The using of funds is lack of planning. There is the phenomenon of management confusion and power and responsibility unclear in the management, use and profit distribution of fund. This phenomenon causes the serious capital loss and lower the efficiency of use. In addition, the lack of normative management, shielding relatives and friends and making no strict accountability, and rely too much on human feelings cause the enterprises in crisis.

\section{The lack and erosion of talents}

With the progress of the age, talents play an more and more important role. Therefore, today's market competition means the talent competition. However, SMEs face with a large number of brain drain problem and outstanding talents shortage.

\section{Unreasonable capital structure}

1) The amount of equity capital and debt capital ratio is not reasonable

Equity capital is the object on which most SMEs in our country rely at the very first, but with the further development of SMEs, the proportion of equity capital is more and more small while the proportion of debt financing is more and more big. This is not only directly affect the refinancing ability of the enterprise, but also make the enterprise encountered severe funding risk and gain crisis. [3]

2) The structural imbalance of equity capital and debt capital itself

Inside the equity capital of the SMEs in our country, the proportion of informal equity and listed stock financing is very low which is far different from the western developed countries. In those countries, from the view of inside debt financing, commercial credit and bank loans are the main source of enterprise liabilities. The proportion of the enterprises getting funds through the issuance of bonds financing is almost zero. Fixed assets bank loans are less and less, and liquidity loan time is less and less. As a result, SMEs is a severe lack of elasticity.

\section{CAUSES OF THE FINANCIAL RISK OF SMES}

\section{A. Acro environment}

SMEs financial risk will be affected by some external environment such as economic factor, political factor, natural factor, legal environment, social factor and science and technology factor. For example, today' s uncertainty of the development of the economic environment changes, the national macroeconomic regulation and control, as well as the fierce competition between modern enterprises will bring risk. The external environment for enterprises is unforeseeable, and often accompanied by many changes. SMEs are lack of adaptability to external environmental changes. They cannot scientific foresee adverse change in the external environment and response delayed. Therefore, for SMEs management, financial risk is great and it will have a major impact on the development of SMEs. However, the external environment is also a double-edged sword, if a business has perfect internal management system, and has strong ability of environmental strain, thus changes in the external environment will also bring good opportunities for development. [4]

\section{B. The micro environment}

1) The market changes and too much inventory are the causes for enterprise financing difficulties and lack of working fund.

First of all, the prices of raw materials and labor rise step by step and the appreciation of the RMB cause a series of problems to make SMEs in a production and operation crisis, and then lower profits or even cause serious losses. Second, there is a common problem that exists in our country SMEs is the inventory occupies too much proportion in liquid assets. Enterprise inventory backlog is too large, less liquid, making the enterprise in a state of high inventory for a long time. As a result, SMEs will take up a lot of liquidity. At this point, if the goods are improperly secured and market changes, it will bring serious loss, resulting in a financial risk. In addition, SMEs have a small amount of capital, they will focus on daily short-tern business activities. This will put spare cash into operating activities at any time, making fewer cash holdings. A series of factors like these can cause SMEs financial risk. [5]

2) Internal financial supervision mechanism is not sound in SMEs causing enterprise financial risk

Many SMEs in China, due to the smaller scale and less labor, they do not to build their own financial monitoring mechanism, or they build the financial monitoring mechanism but it is not effective carried out. In accordance with the relevant provisions on small and SMEs post, the challenge system should be strictly enforced, but SMEs often cronyism. Leaders often appointed their immediate family as the unit cashier work, so the enterprise internal supervision is difficult to perform, even when there is assets loss, they cannot make appropriate treatment and can't form effective binding which lead to the occurrence of financial risk.

3) The lack and erosion of talents and erosion

On one hand, a small amount of capital and small scale brings less benefit to talents. Therefore, SMEs do not attract talent which leads to the erosion of talents in a large amount. On the other hand, SMEs recruitment mechanism is not sound. They can't make a reasonable recruitment plan, thus lost the chance to find the best people. Moreover, SMEs talent training mechanism is not sound. They can't expand the worker's professional quality and skills. As a result, a variety of reasons prove that SMEs have difficulties in retaining talents.

4) SMEs financial risk results from the unreasonable capital structure

Due to its capital is insufficient, SMES face fierce competition in the market competition. If they want to obtain 
rapid development, they must to solve the problem through bank loans. Therefore, the capital structure is not harmonious, because the ratio of debt financing is too high. They depend to much on bank. They have to pay more interest expense which leads the corresponding profit to decline, thus leads to the enterprise's financial burden overweight, and finally debt paying ability drops or even bankruptcy. Visibly, unreasonable capital structure will bring serious crisis to SMEs.

\section{5) The weak consciousness financial risk}

Nowadays, operators, managers and financial personnel of many SMEs in our country have weak consciousness. The financial risk is objective existence. Any activity has certain risks, but most financial personnel lack of market research and understanding of the macroeconomic environment, and there is no enough attention paid to the objective existence of financial risk. This is likely to bring huge losses to the enterprise. At the same time, the imperfection of internal control, unreasonable supervision mechanism and the chaos of the accounting work is one of the main reasons for enterprise financial risk. [6]

6) Financial decision-making errors results in SMEs financial risk.

Many SMEs in our country lack the right investment decision-making mechanism. It is a widespread phenomenon that their financial decisions depend on experience and are subjective. Managers often make decisions with their own subjective consciousness which leads to the occurrence decision-making errors, thus resulting in a financial risk. In addition, if the enterprise market investigation is not comprehensive and accurate, and financial personnel also lack of experience and professional ability, it will also cause financial decision-making errors, bringing the huge financial risk.

\section{PREVENTION AND MEASURES OF SMES FINANCIAL RISK}

\section{A. Strengthen the management of flow of assets such as cash, inventory and accounts receivable}

In the process of enterprise management, accounts receivable amount should not be too much. Therefore, accounts receivable need to recover in time in order to prevent the cash shortage. In the management of accounts receivable aging analysis should be used. SMEs should build provision system of for bad debt to prevent bad debt losses.

\section{B. To establish a perfect internal control system}

Whether enterprise financial internal control mechanism is complete has a direct connection with SMEs.SMEs management regard financial management as the center, while financial management throughout the enterprise economic activities. Therefore, enterprises should design a set of scientific, strict, strongly operational financial internal control mechanism and improve the enterprise's internal control system as well as accounting personnel business skills and the quality of enterprise managers. Furthermore, they should intensify the enterprise internal accounting auditing and supervision of staff, and strict implement for enterprise financial control to ensure the safety of the enterprise funds and reduce the risk of the enterprise management of capital at a large extent. Therefore, improving the SMEs operators awareness of internal accounting control system is very important. Only improve enterprise staff's legal consciousness and strengthen the ego to protect consciousness as well as enterprise department personnel consciousness can SMEs implement internal accounting control system. The financial risk can be greatly reduced to effectively protect the safety of corporate finance and ensure efficient operation of the SMEs internal financial supervision system. [7]

\section{To develop a reasonable salary system and strengthen personnel training mechanism}

If SMEs want to attract the talents, reasonable compensation is indispensable. Therefore, SMEs managers need to formulate the reasonable salary system and offer the outstanding staff certain benefits, and meet the reasonable needs of employees; In addition, it is necessary to strengthen personnel training mechanism and provide training for the staff's professional quality to improve the ability of the workers.

\section{The reasonable adjustment of SMEs capital structure}

It is necessary to optimize the SMEs financial structure and adjust the enterprise debt ratios. Enterprise shall base on the changes in the environment to adjust their own structure such as capital, debt, etc. to keep its scientific, reasonable proportion. The proportion should no more than the bear ability, making liquidity ratio less than 2:1 and making quick adjustment no less than 1:1 ratio. Small and medium-sized enterprises need to achieve a virtuous cycle of capital structure to find a way to study capital structure problem. Starting from establishing reasonable capital structure, regarding high benefit and appropriate risk of SMEs as foothold, they can make reasonable dynamic combination of enterprises capital so as to realize a new rational capital structure. Therefore, the following several key problems need to pay attention to in the management process has:

- SMEs should repay the short-term debt timely and reduce the debt ratio, especially the current liabilities ratio; When there is the rest money, the short term investment should be make timely to speed up the capital operation and avoid waste of funds and shortterm "deposit".[8]

- They should publicize of bonds and improve the debt ratio. If SMEs need a lot of money and debt ratio is low, they can adopt the way of issuing bonds to raise money, so that they can use tax breaks for making their total capital cost reduced.

- They should recover the investment of foreign enterprises and reduce the cost of foreign shares, both reduce the benefits of distributing and lower equity ratio. This can be more effective in control. 


\section{E. Enhance the risk consciousness and build system of financial risk aversion}

Mitigate financial risks effectively is not only something about a few people, but also All the members of the enterprise should give a high degree of attention. The SMEs should hire Professionals with high-quality and high-skill. They should learn to analysis the financial data of the enterprise, and see the potential financial risks from the data, then make active propagandizing of the financial risk awareness and strengthen the study and training of financial risk issues. The financial workers of a enterprise should pay high attention to the enterprise's financial security, guarantee the quality of accounting information and the real of data. The enterprise should also clear all kinds of internal financial relationship, to further strengthen the awareness of responsibility, clear division of labor and clear responsibility. Based on the whole enterprise to do a good job of profit distribution, hold good business interests of all parties concerned, fully arouse the enthusiasm of each department of enterprise in financial management works, give full play to the important role of financial management, make right, duty and benefit unified organically, improve the quality of enterprise's financial work and lay a solid foundation for development of enterprises. [9]Take the example of Electrical appliances sale enterprise, dealers in order to occupy a place in the fierce market competition, must foster a sense of risk and competition, dealers not only need to pay close attention to market information, to understand the needs of the user, but also need to improve electrical appliances service facilities, strengthen a sense of after-sales service and credit, improve their service level, enhance the competitiveness of the enterprises, to further enhance the anti-risk ability of enterprises.

\section{F. To establish investment management decision-making mechanism and make scientific decisions}

Small and medium-sized enterprises should establish the scientific investment management decision-making mechanism. market conditions, should be fully investigated and collected by information personnel to obtain the scientific, reasonable, accurate market information and ensure the high quality of the information; [10]Enterprise financial personnel should be learning in the process of working to further improve all aspects of quality, develop skills, and then ensure the financial management of rigor and accuracy; Managers of enterprises should study all aspects of the research according to the scientific and accurate information and high-quality financial personnel cooperation, so as to make the right investment management decisionmaking and reduce the risk of decision-making.

\section{G. Establishing the warning system of financial risk}

Establishing a system which can reflect the financial position and alarm the financial risk of SMEs plays a crucial role in controlling the financial risk of SMEs effectively.
This system should have an objective reflection and evaluation on the financial risk of SMEs and should look at the actual financial activities and problems of SMEs to reflect the change of financial position of SMEs rapidly, to reflect the relation between SMEs and various links scientifically, and to reflect the potential risk between financial and business activities objectively so that the manager of SMEs can find the financial risk timely and effectively according to the prompt of this system and make the right decision, eliminating the false and retaining the true, making the best judgments, preventing the financial risk continued ascension to cut loss.

\section{CONCLUSION}

From the analysis and discussion above, we can see that financial management plays a vital role in the development of SMEs. Financial risk is inevitable in the operation process of SMEs and how to prevent and control financial risk problem is an important task in financial management works. So, the manager of SMEs and financial workers must attach importance to the problem of financial risk, and put it through the whole financial management works, strengthening the awareness of risk and the enterprise internal supervision mechanism, optimizing the capital structure, improving the financial problems of its own, adapting to real change neatly, to improve the comprehensive strength and be the champion in market competition.

\section{REFERENCES}

[1] Huang Huihui. [J]. Journal of small and medium-sized enterprise financial risk management research, 2003, (01).

[2] Cao Weizhong. Small and medium-sized enterprise financial risk analysis and prevention [J]. Journal of modern economy, 2009, (02).

[3] LiuMin. The theory of small and medium-sized enterprise financial risk effectively avoid [J]. Journal of intelligence, 2013, (11).

[4] Zhang Xianfeng. Shallow theory of small and medium-sized enterprise financial risk prevention strategy [J]. Value engineering, 2012, (19).

[5] Yang Jing month. Introduction to small and medium-sized enterprise financial risk prevention and control [J]. Journal of management, 2013, (8).

[6] Dong Xiaochen. Our country small and medium-sized enterprise financial risk control analysis [J]. Journal of economist, 2013, (6).

[7] NiuYiRan. Small and medium-sized enterprise financial risk early warning and control [J]. Journal of small and medium-sized enterprises, management and technology, 2011 (04).

[8] Hu Lei. Of the financial risk of small and medium-sized enterprises and protection countermeasures study [J]. Journal of financial supervision, 2013, (11).

[9] Yang Jiangchun. Introduction to the enterprise financial risk prevention and control [J]. Journal of economist, 2005, (8).

[10] ] Hu Lei. Small and medium-sized enterprise financial risk causes and prevention countermeasures study [J]. Journal of financial supervision, 2013,(32). 